\title{
Editorial Policy...
}

ACM's Computing Surveys is four years old. Just five short years ago Bill Dorn, our first editor, started with a plan and turned it into a successful reality. He established editorial policies for the new journal that attracted excellent contributions from outstanding authors who were computer professionals. Everyone agreed, after seeing the first one or two issues that the Surveys was an instant success.

The Surveys helped computer people, old and new, to catch up on the latest ideas, concepts, tools, trends, and advances in the field. The papers were technically sound, complete and covered areas of broad interest to a significant cross-section of ACM's membership. Above all, the papers were readable. How does a journal like the Survers function to maintain and even strengthen this tradition? That is the challenge $I$ undertook in accepting the baton from Bill Dorn.

There have been some significant changes in the computer field since Bıll began preparation of Vol. 1, No. 1 of the SurveYs for March 1969. True, even then tens of thousands of students were annually engaged in some study within the computer field. But, today, several thousands annually earn bachelors degrees by majoring in the computer and information sciences, and many hundreds annually complete advanced degrees in these areas-as compared with only handfuls in early 1969. We know that this change was brought about by the great birth and growth rate of degree-granting departments in computer science

The effect of this change has created new opportunities and new challenges for the editor of the Surveys. An increasing number of readers are now capable of benefittıng from tutorial and survey papers presented at advanced levels. At the same time there can hardly have been any diminution of readers who still regard themselves as novices and in need of help in most areas of computer sciences and technology.

The first wave of those with masters and doctorates in computer science have been teaching in Universities for several years. Now, these men and women are able to contribute their technical and expository expertise as Surveys papers. Will they? Do they? You bet! Getting a tutorial paper published in the Survers is increasingly recognized as an achievement on par with a published research paper-as it should be, in my view. We are receiving an increasing number of papers (and proposals to write papers) from such newcomers to the profession. We welcome these contributions and we publish them, too.

Four years ago the editor had to rely for contributions almost exclusively on "old heads" with already-established professional reputations. Now, the authorship exhibits a healthy age distribution. Moreover, although the editor must still exercise intiative to solicit excellent papers, it is much less clear that the carrot needs any longer to be a monetary one. The initial editorial policy and budget permitted the editor to offer a substantial honorarium for every paper published in the Survers. But now, authors know the Surveys as an estabish journal with significant objectives and high standards.

Service of the referees, thanks to their careful selection by Bill Dorn, has been in most cases superb. First rate critical and constructive support has been rendered to the authors. The experience of improving a paper based on the helpful advice of the referees has been rewarding (though often also exhausting) to many a Survers author.

I believe that many professionals who have something to contribute are now willing (and wanting) to offer their manuscripts to the Survers without the need for monetary reward. For this reason, this reward policy is now set aside in favor of the more conventional reward system--that of the recognition and feedback that is gained from the publication itself. Such a step, of course, may be regarded as a calculated risk, but it must be taken, if we are all 
going to reach full maturity as professionals in our new or chosen field.

If the Sunvers has reached the respected status of a true professional journal, as I believe it has, then all of us involved in its production, the editors, advisors, the referees, and the authors, must function as a team-with no one group singled out for special reimbursement. In implementing this policy shift, all authors who have proposed papers but have not yet submitted them have been notified that the policy change will become effective on March 31, 1973. One important consequence of this change should be obvious. Although we will continue to emphasize long papers that cover a broad topic in a thorough fashion, there will now be room for shorter works including what amount to brief notes, and short revisits to topics or papers covered in past issues of the SurveYs

What other editorial policy changes are in the making? One change, important and constructive it is hoped, is in the process of becoming a reality. After several months of study of the manuscript screening, refereeing and approving process, I became convinced that the editor needs an advisory team above the refereeing level. It is doubtful if any one editor can know the computer field in all its aspects, and exercise judgment as to the importance, relevance, and need for papers in every subject area.

To appoint an associate editor for each area seems not to be a meaningful solution for a journal that may publish fewer than twenty papers per year. Accordingly, I am in the process of gaining the support of a team of advisory editors who are senior contributors to the computer field on a broad front and on whose judgment on the question of what's worth doing and publishing in the Survers I can thoroughly rely. In general, each new paper that is received will be sent to an advisory editor for a firstlevel opinion as to its worthwhileness (that subject and that approach) for the Survers Normally these advisors will not offer a technical service. They will not referee the paper at a technical level. If the advisor agrees that the paper should be considered seriously, I will then send it out to referees who are professionals and technically active in the area covered by the paper. The paper will then begin its customary "passage" toward publication.

To make this new approach work, my role as a dispatcher and expeditor must necessarly increase and my role as editor and judge will of necessity become, in large part, distributed among my advisors. However, I am confident that this new plan can speed up rather than slow down the whole editorial process.

What characterizes a SuRvers paper and to what extent should this "profile" be expected to change in the near future? A hard question to answer, indeed! If we were to survey the Surveys readers, chances are we would recelve one set of diverse opinions as to what readers want If we were to survey the Surveys authors or potential authors, we would undoubtedly get a different set of diverse opinions as to what they think should be published. To preserve my sanity, I do not currently plan to do either survey in any complete sense Instead, I shall continue to keep two open ears listening at all times and ask for opinions, including yours here and now Below are my present views -the guidelines that I currently offer potential authors, and employ as I judge the papers that are submitted Please see if you agree with me, and let me know what you think.

First, a good tutorial paper covering an area of the computer field that has recently become important or better understood will get top priority. A tutorial should be long enough and clear enough to excite the reader's imagination and to teach the reader. . using models, clean and simple notation, preferably using as informal a style as possible, and, above all, using a well-selected and slowly-enough-developed set of lucid and insight-transferring examples. A reader should be able to pick up such a tutorial and notice by reading no more than the title and abstract that the article covers a topic he has already wanted to learn about.

The body of the tutorial should be so interesting that the paper can be read, regardless of its length, in one or at most two 
sittings. Finally, the tutorial should provide the reader with a guided list of references where further information can be obtained. A tutorial should introduce understanding that may have been recently acquired (preferably generally accepted or respected), but it should not introduce and discuss recent research. Tutorials are not intended to be serving trays from which advanced graduate students, previously unable to identify a suitable dissertation problem, can find one already cut in a neat square.

I have given my view of the ideal tutorial. But, what of the survey article? By its nature a survey artıcle is not also a tutorial, else it would be a book. A survey article should rely on the reader's general knowledge of the areas surveyed, and should be as complete as possible in its listing of relevant subtopics and work reported in these subtopics. The text of the survey can be brief, letting the bibliography that attends it and the index into it be as long, thorough, and up-to-date as required. Survey articles of great value exercise good judgment by marking those references that are notable and by explaining why-or by omitting those references that are not worth mentioning albeit identifying the type of work that has been omitted and why. An excellent survey article is likely to be given preference over a tutorial that is rated only good.

I hope all these editorial policies and guidelines meet with general approval, and I will do my best to carry out these policies for the continued improvement of the Survers. I intend to retain a flexible posture, however, and will, of course, respond to clear feedback. The role of editor is not that of autocrat but that of servant. I hope never to forget this distinction while I am your editor.

-Elliott I. Organick 